$$
\begin{aligned}
& \text { Pontifícia Universidade Católica } \\
& \text { DO RIO DE JANEIRO }
\end{aligned}
$$

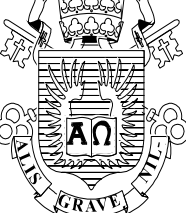

Raphael Diego Neves Martins

\title{
Formar para Civilizar: A revista Minerva Brasiliense (1843-1845) na construção da Nação Brasileira
}

\section{Dissertação de Mestrado}

Dissertação apresentada como requisito parcial para obtenção do grau de Mestre pelo Programa de Pós-Graduação em História Social da Cultura do Departamento de História do Centro de Ciências Sociais da PUC-Rio.

Orientador: Prof. Marco Antonio Villela Pamplona 


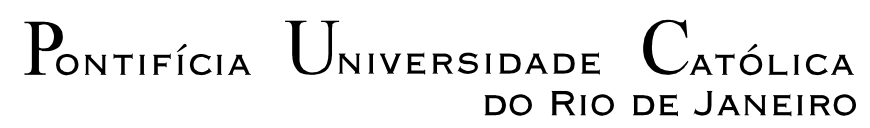

DO RIO DE JANEIRO

\title{
Raphael Diego Neves Martins
}

Formar para Civilizar:

A revista Minerva Brasiliense (1843-1845) na construção da

Nação Brasileira

Dissertação apresentada como requisito parcial para obtenção do grau de Mestre pelo Programa de Pós-Graduação em História Social da Cultura do Departamento de História do Centro de Ciências Sociais da PUC-Rio. Aprovada pela Comissão Examinadora abaixo assinada.

\author{
Prof- Marco Antonio Villela Pamplona \\ Orientador \\ Departamento de História \\ PUC-Rio
}

Profo IImar Rohloff de Mattos

Departamento de História

PUC-Rio

Prof ${ }^{a}$ Márcia de Almeida Gonçalves

Departamento de História

UERJ

Prof ${ }^{\text {a }}$ Mônica Herz

Vice-Decana de Pós-Graduação do Centro de Ciências Sociais

PUC-Rio

Rio de Janeiro, 01 de setembro de 2011. 
Todos os direitos reservados. É proibida a reprodução total ou parcial do trabalho sem a autorização da universidade, do autor e do orientador.

\section{Raphael Diego Neves Martins}

Professor Tutor e Assistente da Coordenação do Curso de Licenciatura em História, modalidade à Distância, da Pontifícia Universidade Católica do Rio de Janeiro, com ênfase em História do Brasil e História da América. Possui bacharelado e licenciatura em História pela Pontifícia Universidade Católica do Rio de Janeiro (2007).

Ficha Catalográfica

Martins, Raphael Diego Neves

Formar para civilizar: a revista Minerva Brasiliense (18431845) na construção da nação brasileira / Raphael Diego Neves Martins ; orientador: Marco A. Pamplona. - 2011. 130f. ; $30 \mathrm{~cm}$

Dissertação (mestrado)-Pontifícia Universidade Católica do Rio de Janeiro, Departamento de História, 2011. Inclui bibliografia

1. História - Teses. 2. História social da cultura. 3. Nação. 4. Imprensa. 5. Literatura. 6. Romantismo. 7. Instrução pública. 8. Progresso. 9. Civilização. 10. Império do Brasil. I. Pamplona, Marco A. II. Pontifícia Universidade Católica do Rio de Janeiro. Departamento de História. III. Título.

CDD: 900 
"Corra, corra atrás do seu ar puro Faça mole o caminho duro, sem desanimar (...) Para chegar ao fim de uma longa caminhada E ter feliz jornada"

Dedico este trabalho à minha família e a todos os que, de alguma forma, me ajudaram a chegar até aqui. 


\section{Agradecimentos}

Ao CNPq, pela concessão da bolsa ao longo do mestrado.

Ao meu orientador, Marco Antônio Pamplona, pela confiança depositada em mim desde o começo de minha pesquisa.

Ao mestre Ilmar Rohloff de Mattos e a professora Márcia Gonçalves pelos valiosos conselhos.

Aos professores, Selma Rinaldi, Luís Reznik, Antonio Edmilson, Maísa Mader e Margarida de Souza Neves.

Aos secretários do departamento de História, Cleusa, Moisés, Edna, Anair e Cláudio.

Aos amigos de longa data Raoni Rabello e Bruno Magalhães.

Ao amigo Pablo Mattos, que nas suas palavras, essa amizade só pode ser explicada por "aquilo que não se vê".

Ao Leandro Janke, pela amizade que não tem hora nem lugar.

Aos queridos amigos Mário Ângelo, Samantha Valério, Heitor Velasco, Rebecca Coscarelli, Isabel Auler, Daniela Daflon, Ana Cristina Frias, Cláudio Daflon, Roberto Azevedo, Maria Aparecida dos Santos, Paula Belém, João Marcelo Dias, Hugo Barbosa, Vanessa Barbosa, Denise Mourthé, Maurício Adelino, Marina Schneider, Manoela Barbosa, Luisa Souto, Deri Santana, e tantos outros que sempre estiveram ao meu lado.

A Érica Szabo, pelo amor, carinho, companhia constante, palavras de apoio e incentivo nos últimos meses de cansaço e ansiedade. 
A Talia e Samyra por todo o carinho e eterna amizade dentro do seio familiar.

Aos meus pais, Daniel e Cilene, aos meus irmãos, Daniel e Marcelo, aos meus sobrinhos, Bernardo e Marina, pelo apoio constante e amor incondicional. 


\section{Resumo}

Martins, Raphael Diego Neves; Pamplona, Marco Antonio Villela. Formar para Civilizar: A revista Minerva Brasiliense (1843-1845) na construção da Nação Brasileira. Rio de Janeiro, 2011. 130p. Dissertação de Mestrado - Departamento de História, Pontifícia Universidade Católica do Rio de Janeiro.

Esta dissertação pretende empreender uma análise da revista Minerva Brasiliense, que teve como redator-chefe Francisco de Sales Torres Homem e como seu responsável Santiago Nunes Ribeiro. Publicado no Rio de Janeiro entre os anos de 1843 e 1845, este periódico foi bastante importante na constituição da nação brasileira. À época, nação, progresso e civilização foram conceitos-chave $\mathrm{e}$ recorrentes para a maioria dos ensaios veiculados na revista, e também para outros periódicos do período. A revista está sendo pensada como um instrumento de formação e legitimação de uma determinada Ordem e Civilização; como o primeiro porta-voz de certas concepções sobre o que é ser brasileiro e defensora de um projeto político deliberado para modernização e promoção da civilização no país.

\section{Palavras chave}

Nação; Imprensa; Literatura; Romantismo; Instrução Pública; Progresso; Civilização; Império do Brasil. 


\section{Abstract}

Martins, Raphael Diego Neves; Pamplona, Marco Antonio Villela (Advisor). Educate to Civilize: The journal Minerva Brasiliense (18431845) in the construction of the Brazilian Nation. Rio de Janeiro, 2011. 130p. MSc. Dissertation - Departamento de História, Pontifícia Universidade Católica do Rio de Janeiro.

This dissertation intends to undertake an analysis of the journal Minerva Brasiliense, that had as chief editor Francisco de Sales Torres Homem and as it's responsible Santiago Nunes Ribeiro. Published in Rio de Janeiro between the years of 1843 and 1845, this periodical was quite important in the constitution of the Brazilian nation. At the time, nation, progress and civilization were key concepts and were recurrent in most of the essays circulated in the journal, and also in other periodicals of the period. The magazine is being thought of as an instrument in the formation and legitimization of a determined Order and Civilization; as the first spokesman for certain concepts about what it is to be Brazilian and a defender of a deliberate political project for the modernization and the promotion of civilization in the country.

\section{Keywords}

Nation; Press; Literature; Romantism; Public Instruction; Progress; Civilization; Empire of Brazil. 


\section{Sumário}

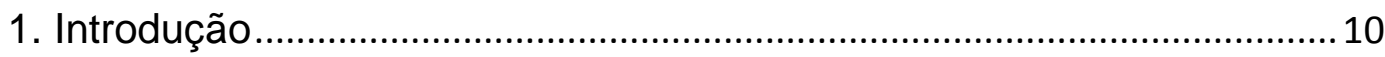

2. Nos Caminhos da Imprensa: Política, Cultura e

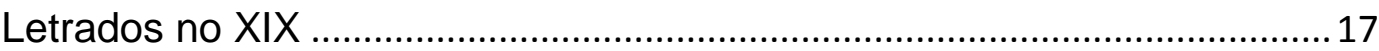

3. Minerva Brasiliense: Romantismo, Nação e Literatura ............................4 45

4. Nas rodas da História: Instruir para Civilizar.............................................96

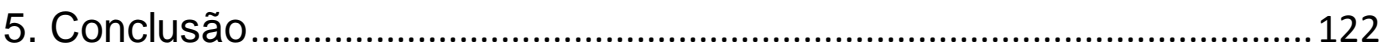

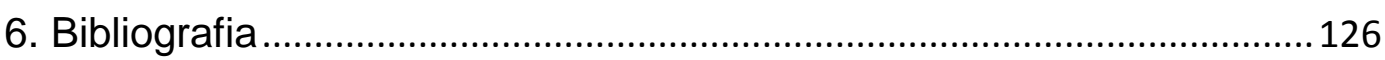

